\title{
Invasion by Neisseria meningitidis varies widely between clones and among nasopharyngeal mucosae derived from adult human hosts
}

\author{
Robert Townsend, ${ }^{1}$ Linda Goodwin, ${ }^{1}$ Tania M. Stevanin, ${ }^{1}$ \\ Paul B. Silcocks, ${ }^{2}$ Andrew Parker, ${ }^{1}$ Martin C. J. Maiden ${ }^{3}$ \\ and Robert C. Read ${ }^{1}$
}
1 Division of Genomic Medicine, F Floor, Sheffield University Medical School, Beech Hill Road, Sheffield S10 2RX, UK
2 School of Public Health, University of Nottingham, UK
3 Wellcome Trust Centre for the Epidemiology of Infectious Disease, Department of Zoology, University of Oxford, UK

\author{
Author for correspondence: Robert C. Read. Tel: +44 114272 4072. Fax: +44 1142739926. \\ e-mail:r.c.read@shef.ac.uk
}

Colonization of the human nasopharynx is a feature of some species of Neisseria, and is a prerequisite of invasive meningococcal disease. The likelihood of colonization by Neisseria meningitidis varies widely between humans, and very few develop invasive disease. Explants of nasal mucosa derived from adult patients with non-allergic nasal obstruction were infected experimentally with Neisseria spp. At intervals over $18 \mathrm{~h}$ incubation, washed explants were homogenized, and viable bacteria were counted. To estimate bacterial invasion of mucosa, explants were exposed to $0.25 \%$ sodium taurocholate for $30 \mathrm{~s}$ prior to homogenization. N. meningitidis was recovered from the mucosa and the organism invaded and replicated within the tissue, in contrast to $N$. lactamica and $N$. animalis $(n=9, P<0.008)$. $N$. meningitidis isolates of clones ET-5, ET-37 and lineage III were recovered from and invaded tissue, but strains of clones A4, A: subgroup I, A: subgroup III and A:subgroup IV-1 did not invade $(n=6)$. To measure host variation, survival of $N$.

meningitidis within nasal mucosa of $\mathbf{4 0}$ different human donors was measured. Intra-class correlation of replicates was 0.97 , but the coefficient of variation of recovered viable counts was $1335 \%$ after $4 \mathrm{~h}$ and $77 \%$ after $18 \mathrm{~h}$ incubation. It is concluded that the distinctive colonization and disease potential of Neisseria spp. may be partly a consequence of their ability to invade and survive within human nasopharyngeal mucosa, but that this is influenced greatly by genetic or environmental factors operating on the host mucosa. This is consistent with the unpredictable epidemiology of meningococcal disease.

Keywords: pathogenesis, colonization, Neisseria lactamica, Neisseria animalis

\section{INTRODUCTION}

Colonization and invasion of nasopharyngeal mucosa is the first step in the pathogenesis of meningococcal disease. Supporting evidence for this is the correlation between the prevalence of community carriage and the occurrence of meningococcal disease (Broome, 1986). During non-epidemic periods, the baseline prevalence of nasopharyngeal carriage of meningococci is $5-10 \%$ but it is considerably higher in certain populations such as military personnel (Riordan et al., 1998), and in house-

Abbreviation: $\mathrm{MBC}$, mean bactericidal concentration. holds of cases (Greenfield \& Feldman, 1967) and smokers (Stuart et al., 1989). There is good evidence that host factors determine partly the success of Neisseria meningitidis within the nasopharynx, as some individuals appear resistant to acquisition of carriage, whilst others carry the organism chronically or intermittently (Rake, 1934). The precise site within the nasopharynx that N. meningitidis colonizes and invades is not known, but during natural carriage, the organism can be isolated both from the nose and from the throat (Olcen et al., 1979), and can be observed by immunofluorescence deep within tonsillar tissue (Sim et al., 2000).

Humans can be colonized by commensal Neisseria 
including $N$. lactamica, which rarely causes disease. Colonization by N. lactamica is frequent in infants but declines to relatively low rates in teenagers and adults (Cartwright et al., 1987; Gold et al., 1978). It is possible that $N$. lactamica displaces $N$. meningitidis from the nasopharynx in childhood and produces natural immunity against invasive meningococcal disease (Coen et al., 2000) as a consequence of immunogenic epitopes shared between N. lactamica and N. meningitidis.

Organ culture permits the study of the interaction of $N$. meningitidis with a tissue which has physiologically relevant cellular and matriceal components. A number of groups have used organ culture to study biology of the interaction of $N$. meningitidis with human airway mucosa. Meningococci attach selectively to non-ciliated columnar cells, and during this process microvilli of non-ciliated cells elongate and surround the organisms. Meningococci appear to undergo parasite-directed endocytosis and are observed in subepithelial tissues adjacent to lymphoid tissue after prolonged incubation (Stephens et al., 1983), though this is observed in a minority of explants (Read et al., 1995). Pili and capsular polysaccharide both influence association of $N$. meningitidis with nasopharyngeal mucosa (Rayner et al., 1995; Stephens et al., 1993), but concurrent switching of multiple phase-variable bacterial surface components such as these, and outer-membrane proteins including Opa, appears to occur during successful invasion of this tissue (de Vries et al., 1996).

In this work, a model of survival of Neisseria spp. within human nasopharyngeal mucosa was developed, and the success of various Neisseria spp. within this tissue was compared. The variation of survival of $N$. meningitidis with the mucosae of a large number of donor human tissues was then measured.

\section{METHODS}

Bacteria. Strain K454 (B15P1.7,16,L3,7,9, sulphonamide resistant) is an isolate of $N$. meningitidis taken from a child during an epidemiological investigation into an outbreak of meningococcal disease in a Gloucestershire Health District of the UK (Cartwright et al., 1987). Reference isolates of $N$. lactamica and $N$. animalis were used. Also seven representative isolates derived from different clusters or clones of $N$. meningitidis were used, and these are listed in Table 1. Strains were stored in liquid nitrogen. On the experimental day, $15 \mu \mathrm{l}$ of overnight broth culture was transferred to fresh MuellerHinton Broth in $6 \mathrm{ml} \mathrm{screw-capped} \mathrm{bottles} \mathrm{and} \mathrm{incubated} \mathrm{to}$ mid-exponential phase for $4 \mathrm{~h}$ at $37^{\circ} \mathrm{C}$ on a rolling stage. The growth was centrifuged at $2000 \mathrm{~g}$, washed and centrifuged three times with $1 \mathrm{ml}$ phosphate-buffered saline (PBS). Twenty microlitres of the final wash diluted in PBS was examined using spectrophotometry to permit adjustment to the required inoculum.

Western blots. Expression of Opa and PilC was detected by Western blotting with (i) 4B12/C11 anti-Opa (gift of X. Nassif and P. Morand), (ii) 18P4 anti-PilC (gift of J. Moir), a rabbit polyclonal which recognizes both PilC1 and PilC2. Secondary detection was conducted using horseradish-peroxidase-conjugated antibodies with the ECL chemiluminescence system (Amersham Pharmacia Biotech).
Organ culture. A modified technique of organ culture using explants of human nasal turbinate mucosa was used (Jackson et al., 1996; Read \& Goodwin, 2001). Inferior turbinates derived from patients with non-allergic nasal obstruction were resected in all cases by the same surgeon. All donors gave informed consent and the research was approved by the South Sheffield Research Ethics Committee (96/260). Tissue was transported to the laboratory in Minimal Essential Medium (MEM) containing penicillin (50000 units $\mathrm{l}^{-1}$ ), streptomycin $\left(50 \mathrm{mg} \mathrm{l}^{-1}\right)$ and gentamicin $\left(50 \mathrm{mg} \mathrm{l}^{-1}\right)$ and dissected to produce 3-4 mm squares of mucosa, after removal of the anterior pole of the turbinate, which can be heavily populated by squamous epithelium. Tissue was incubated in antibioticcontaining MEM for a total of $4 \mathrm{~h}$ before being immersed in $20 \mathrm{ml}$ antibiotic-free MEM for $1 \mathrm{~h}$. Homogenates of explants treated in this way exhibited no antibiotic activity in bioassay (data not shown), suggesting that the methods used did not result in accumulation of antibiotics in tissue. A $3 \mathrm{~cm}$ Petri dish was placed within the perimeter of a $10 \mathrm{~cm}$ Petri dish, and Visking tubing (30/32; Scientific Instruments) placed across the inner dish to irrigate the explant with antibiotic-free MEM $(7 \mathrm{ml})$ placed in the outer dish. Explants were then placed cutsurface downwards onto the filter paper across the centre of the inner dish and $1 \%$ molten agar $\left(\right.$ at $40^{\circ} \mathrm{C}$ ) was placed around the explant to hold its orientation. The agar set rapidly, and then tissue was bathed in $200 \mu \mathrm{l}$ MEM until it was ready for inoculation with bacteria. In experiments to validate the invasion assay, explants were treated with and without cytochalasin $\mathrm{D}\left(1 \mu \mathrm{g} \mathrm{ml}^{-1}\right)$, which was added to all media bathing the tissue from arrival in the laboratory until completion of experiments.

Measurement of survival and penetration by $\boldsymbol{N}$. meningitidis. To measure survival of Neisseria spp. within the organ culture system, the MEM bathing the tissue was aspirated and $100 \mu \mathrm{l}$ PBS containing a suspension of Neisseria spp. was placed onto the surface of the air-exposed explant. The whole was then transferred to an incubator at $37^{\circ} \mathrm{C}$ in humidified $5 \% \mathrm{CO}_{2}$ and incubated over a period of $24 \mathrm{~h}$. At intervals over the period of incubation, explants were carefully removed from the agar and transferred to PBS $(6 \mathrm{ml})$ in a bijou container. Explants were vortexed and washed through three changes of PBS, then homogenized in a 1-shot cell disrupter (Warwick Systems, Warwick, UK). The total number of bacteria within each homogenate was then estimated by viable counting. A technique described previously (Read et al., 1999) was used to estimate bacterial invasion of the tissue. Explants were immersed in $0.25 \%(\mathrm{w} / \mathrm{v})$ sodium taurocholate (bile salts) (Sigma) for $30 \mathrm{~s}$. Tissue was then immediately transferred to three changes of PBS in a universal container prior to homogenization in the 1 -shot cell disrupter. This concentration of sodium taurocholate kills a suspension of $10^{7}$ N. meningitidis within $30 \mathrm{~s}$ (Read et al., 1999). The mean bactericidal concentration (MBC) of sodium taurocholate for each strain under test was measured by a standard dilutional technique. Prior to homogenization, all tissue samples were weighed and the viable counts of the homogenates of both sodium-taurocholate-treated and untreated explants were expressed per $\mathrm{mg}$ tissue. Where required, an 'invasive fraction' was calculated by dividing the viable count of sodiumtaurocholate-treated explants by the viable count of untreated explants. Output bacteria were checked by Gram staining. Uninfected control explants were included so that any contamination could be identified.

Statistical analysis. For multiple comparisons between strains, statistical analysis was conducted by two-way ANOVA. Residuals were checked for normality using the Anderson-Darling 
Table 1. Strains used in this study

\begin{tabular}{|c|c|c|c|c|c|}
\hline Species & $\begin{array}{l}\text { NCTC no., acquisition no. } \\
\text { or other identifier }\end{array}$ & Clonal group & Serogroup & Opa & PilC \\
\hline N. meningitidis & K454 & ET-5 & B & + & + \\
\hline N. lactamica & 10617 & NA & NA & - & + \\
\hline N. animalis & 10212 N462 & NA & NA & - & - \\
\hline N. meningitidis & z1275 & A:subgroup I & A & - & + \\
\hline N. meningitidis & z3524 & A:subgroup III & A & + & + \\
\hline N. meningitidis & $\mathrm{z} 4421$ & A: subgroup IV-I & $\mathrm{A}$ & + & + \\
\hline N. meningitidis & z4662 & A4 & $\mathrm{B}$ & + & + \\
\hline N. meningitidis & $\mathrm{z} 4242$ & ET-37 & $\mathrm{C}$ & + & + \\
\hline N. meningitidis & z4673 & Lineage III & B & + & + \\
\hline N. meningitidis & z3842 & ET-5 & B & + & + \\
\hline
\end{tabular}

NA, Not applicable.

test. To compare inter-subject variability, data from 40 patients were normalized by logarithmic transformation, prior to analysis of variance. Intra-class correlation between replicates was based on variance components and estimated by two-way ANOVA.

\section{RESULTS}

\section{Validation of organ culture model}

Results of preliminary experiments to refine and validate the model are shown in Fig. 1. Explants from a single human host were inoculated with 10-fold incremental doses of N. meningitidis from $10^{2}$ c.f.u. to $10^{7}$ c.f.u. (Fig. 1a). With inocula of $10^{2}$ c.f.u. there was no recovery of N. meningitidis from explants homogenized at $4 \mathrm{~h}$. With inocula of $10^{3}$ and $10^{4}$ c.f.u., small numbers of organisms were recovered after $4 \mathrm{~h}$ incubation but none after $18 \mathrm{~h}$ incubation. Inocula of $10^{6}$ and $10^{7}$ c.f.u. resulted in recovery of organisms after $4 \mathrm{~h}$ incubation, with replication to higher counts by $18 \mathrm{~h}$. With an inoculum of $10^{5}$ c.f.u. there was recovery of bacteria after $4 \mathrm{~h}$ but numbers declined thereafter. After treatment with sodium taurocholate, bacteria were only recovered after both $4 \mathrm{~h}$ and $18 \mathrm{~h}$ incubation from explants inoculated with $10^{7}$ c.f.u. (data not shown).

Fig. 1(b) demonstrates the yield of $N$. meningitidis (strain K454) in six experiments using human nasopharyngeal explants derived from six different human hosts. At an initial inoculum of $1.9 \pm 0.5 \times 10^{7}$ c.f.u. there was a gradual increase of the number of organisms recovered from untreated washed homogenates of ex-
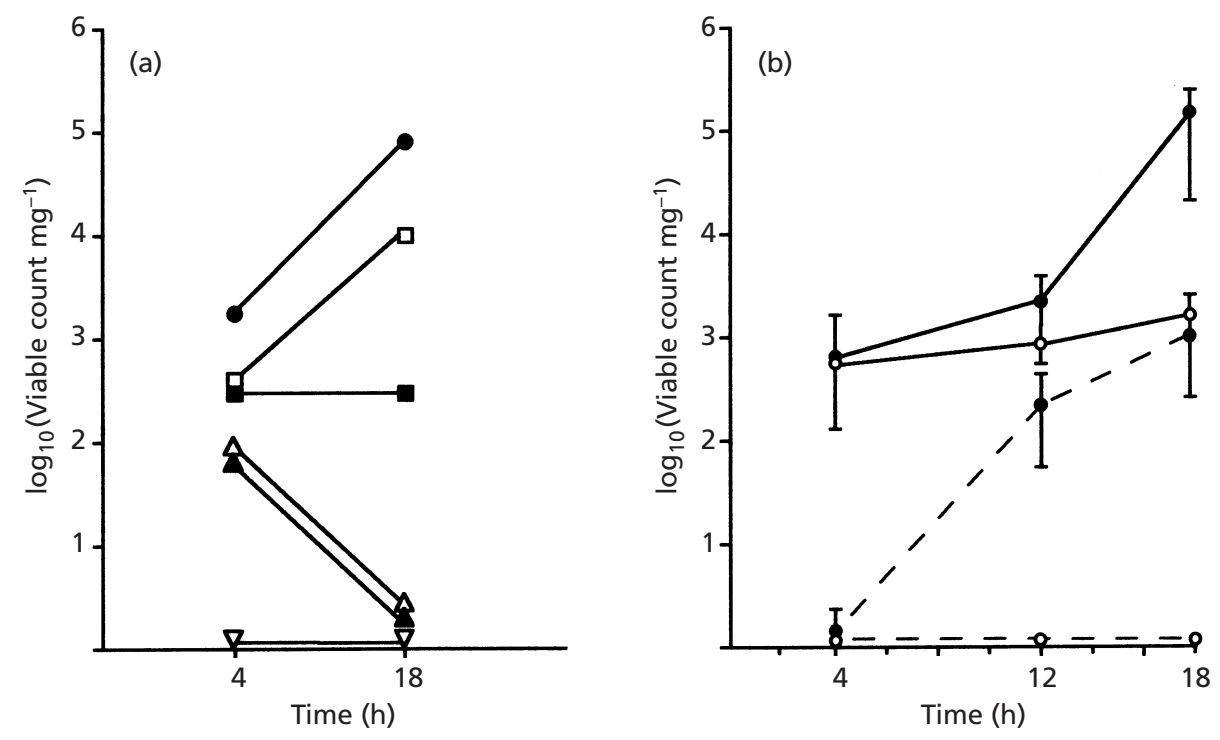

Fig. 1. Growth of $N$. meningitidis strain $K 454$ in nasopharyngeal explant mucosa. (a) Viable counts recovered from homogenized tissue following inoculation of $10^{2}$ c.f.u. $(\nabla), 10^{3}$ c.f.u. $(\boldsymbol{\Delta}), 10^{4}$ c.f.u. $(\triangle), 10^{5}$ c.f.u. $(\boldsymbol{\square}), 10^{6}$ c.f.u. $(\square)$ and $10^{7}$ c.f.u. (O) after $4 \mathrm{~h}$ and $18 \mathrm{~h}$ incubation. (b) Viable counts of $N$. meningitidis strain $\mathrm{K} 454$ from nasal mucosa derived from six human donors over $18 \mathrm{~h}$ incubation, using tissue exposed $(O)$ or not exposed $(0)$ to cytochalasin D. The dashed graphs show the number of bacteria recovered after sodium taurocholate treatment $(n=6)$. 
Table 2. Survival of representative strains of $N$. meningitidis, $N$. lactamica and $N$. animalis in human nasopharyngeal mucosa in vitro

Data are expressed as viable counts $(\mathrm{mg} \text { explant tissue })^{-1}$; means \pm SEM, $n=9$ experiments. $* P=0 \cdot 04, N$. lactamica versus $N$. meningitidis. $* P=0 \cdot 004, N$. animalis versus $N$. meningitidis; $P=0 \cdot 024, N$. animalis versus $N$. lactamica (Mann-Whitney test). Ns, Not significant.

\begin{tabular}{|c|c|c|c|c|c|}
\hline & \multirow{3}{*}{$\begin{array}{l}\text { Inoculum } \\
\text { (c.f.u.) }\end{array}$} & \multicolumn{4}{|c|}{ Bacteria recovered } \\
\hline & & \multicolumn{2}{|c|}{$4 \mathrm{~h}$} & \multicolumn{2}{|c|}{$18 \mathrm{~h}$} \\
\hline & & Total & $\begin{array}{c}\text { After sodium } \\
\text { taurocholate } \\
\text { treatment }\end{array}$ & Total & $\begin{array}{c}\text { After sodium } \\
\text { taurocholate } \\
\text { treatment }\end{array}$ \\
\hline N. meningitidis & $1.9 \pm 0.7 \times 10^{7}$ & $104 \cdot 1 \pm 23 \cdot 6$ & 0 & $1650 \cdot 1 \pm 1220 \cdot 8$ & $75 \cdot 9 \pm 28 \cdot 3$ \\
\hline N. lactamica & $1.3 \pm 0.6 \times 10^{7}$ & $133 \cdot 4 \pm 71 \cdot 3$ (NS) & 0 & $388 \cdot 3 \pm 250 \cdot 5 \%$ & 0 \\
\hline N. animalis & $2 \cdot 5 \pm 0.8 \times 10^{7}$ & $155 \cdot 6 \pm 57 \cdot 5(\mathrm{NS})$ & 0 & $3 \cdot 8 \pm 2 \cdot 0^{* * *}$ & 0 \\
\hline
\end{tabular}

plant tissue over $18 \mathrm{~h}$ incubation. After treatment of explants with sodium taurocholate very few bacteria were recovered from explants incubated for $4 \mathrm{~h}$ (mean invasive fraction $0 \cdot 024$ ). However, this gradually increased and by $18 \mathrm{~h}$ a higher proportion of organisms was recovered after sodium taurocholate treatment, with a mean invasive fraction of $0 \cdot 14$.

Treatment of tissue with the f-actin polymerization inhibitor cytochalasin D reduced the yield of strain K454 from homogenized explants (Fig. 1b). Following sodium taurocholate treatment, no viable bacteria were recovered from explants exposed to cytochalasin, supporting the utility of sodium taurocholate in isolating bacteria internalized into the mucosa.

The MBC of sodium taurocholate for all strains used in the study was $0.03 \%$. Thus, the concentration of sodium taurocholate used to kill extra-mucosal bacteria $(0 \cdot 25 \%)$ was more than eightfold higher than the MBC. To determine whether treatment with sodium taurocholate was killing all extra-mucosal neisseriae without killing those that had penetrated mucosa, explants infected with strain K454 for $24 \mathrm{~h}$ were washed, treated with sodium taurocholate and then washed a further three times prior to vigorous rolling over the surface of blood agar. No colonies of Neisseria grew over $24 \mathrm{~h}$ incubation $(n=3)$. However, when the same explants were homogenized, viable counts of strain K454 were recovered from all three, at similar concentrations to those shown in Fig. 1(b) (data not shown). To demonstrate that sodium taurocholate did not penetrate the tissue, uninfected explants were treated with sodium taurocholate $0.25 \%$ for $30 \mathrm{~s}$, washed, homogenized, and the homogenate was placed in wells cut into blood agar. No bactericidal activity was observed.

\section{Comparison of $\boldsymbol{N}$. meningitidis, $\boldsymbol{N}$. lactamica and N. animalis}

To determine whether this model discriminates among representative pathogenic and non-pathogenic Neisseria spp., explants were infected with N. meningitidis (strain
K454), and NCTC strains of N. lactamica and N. animalis. The strain of N. lactamica used in this study expressed PilC but not Opa, whilst the strain of $N$. animalis expressed neither (see Table 1). Data from nine repeated experiments each using tissue from a different human host, in which Neisseria recovery after $4 \mathrm{~h}$ and $18 \mathrm{~h}$ incubation was compared, are shown in Table 2. Explants weighed in the range $28-36 \mathrm{mg}$, with no significant difference observed between experimental limbs. There was no significant difference between the inoculum of organisms, and no significant difference between viable counts of homogenates of untreated explants after $4 \mathrm{~h}$ incubation. In contrast, the counts of $N$. meningitidis recovered from untreated explants by 18 h of incubation was significantly greater than those of $N$. lactamica and N. animalis. Very little change in the recovered counts of $N$. lactamica was seen over $18 \mathrm{~h}$ of infection; $N$. animalis was recovered at much lower counts from untreated explants after $18 \mathrm{~h}$. In these experiments, there was no recovery of bacteria from explants incubated for $4 \mathrm{~h}$ and subsequently treated with sodium taurocholate; however, there was recovery of N. meningitidis from sodium-taurocholate-treated explants at $18 \mathrm{~h}$, in contrast to $N$. lactamica and $N$. animalis, which were not recovered from sodium taurocholate-treated explants. Minor variations in inoculum into the model were observed but when the analysis was adjusted to account for this, all significant associations remained.

\section{Comparison of clonally diverse isolates of N. meningitidis}

Eight representative isolates of diverse clones of $N$. meningitidis were then grown to mid-exponential phase, washed, and each was inoculated onto a pair of explants derived from the same donor and incubated for $18 \mathrm{~h}$, whereupon explants were homogenized with and without prior sodium taurocholate treatment. This required the use of 16 explants derived from the same donor on each experimental day. All strains were found to express 
Table 3. Survival of representatives of clones of $N$. meningitidis in human nasopharyngeal mucosa in vitro over $18 \mathrm{~h}$ incubation

Data are expressed as viable counts (mg explant tissue $)^{-1}$; means \pm sEM, $n=6$ experiments.

\begin{tabular}{|c|c|c|c|c|}
\hline \multirow[t]{2}{*}{ Clonal group } & \multirow[t]{2}{*}{ Serogroup } & \multirow{2}{*}{$\begin{array}{l}\text { Inoculum } \\
\left(\text { c.f.u. } \times 10^{7}\right)\end{array}$} & \multicolumn{2}{|c|}{ Bacteria recovered } \\
\hline & & & Total $\left(\times 10^{3}\right)$ & $\begin{array}{l}\text { After sodium taurocholate } \\
\text { treatment }\left(\times 10^{3}\right)\end{array}$ \\
\hline A:subgroup I & $\mathrm{A}$ & $2 \cdot 1 \pm 1 \cdot 3$ & $8 \cdot 6 \pm 13 \cdot 0$ & 0 \\
\hline A: subgroup III & $\mathrm{A}$ & $1 \cdot 5 \pm 3 \cdot 6$ & $61 \cdot 8 \pm 133 \cdot 4$ & 0 \\
\hline A: subgroup IV-1 & A & $3 \cdot 3 \pm 3 \cdot 1$ & $2 \cdot 8 \pm 4 \cdot 2$ & 0 \\
\hline A4 & $\mathrm{B}$ & $1 \cdot 7 \pm 1 \cdot 3$ & $18 \cdot 4 \pm 38 \cdot 5$ & 0 \\
\hline ET-37 & $\mathrm{C}$ & $1 \cdot 9 \pm 2 \cdot 0$ & $13 \cdot 3 \pm 12 \cdot 5$ & $1 \cdot 0 \pm 1 \cdot 9$ \\
\hline Lineage III & $\mathrm{B}$ & $0.8 \pm 0.6$ & $483 \cdot 1 \pm 999 \cdot 6$ & $8 \cdot 1 \pm 15 \cdot 1$ \\
\hline ET-5 & $\mathrm{B}$ & $0 \cdot 7 \pm 0 \cdot 4$ & $264 \cdot 8 \pm 121 \cdot 1$ & $5 \cdot 6 \pm 13 \cdot 5$ \\
\hline ET-37 & $\mathrm{B}$ & $3 \cdot 2 \pm 2 \cdot 7$ & $71 \cdot 5 \pm 57 \cdot 5$ & $4 \cdot 5 \pm 6 \cdot 4$ \\
\hline
\end{tabular}

Opa and PilC, except N. meningitidis Z1275 (A: subgroup I) which did not express Opa. Data from experiments repeated six times with tissue from different donors are shown in Table 3. There was no significant difference between the inoculum size of the different isolates. Recovery of bacteria from explants incubated for $18 \mathrm{~h}$ only was measured. There was no significant difference between donor tissues in weight of tissue or recovery of bacteria from untreated explants. In contrast, isolates of A : subgroup I, A : subgroup III, A : subgroup IV-1 and A4 were consistently absent from sodium-taurocholate-treated explants, whereas strains of ET-37, lineage III and ET-5 were consistently recovered within such mucosa of all six donor tissues used. It was noted that the ET-5 strain was recovered in higher counts than was seen in experiments described in Table 2 (in which another ET-5 strain, K454) was used. This was likely due to wide inter-donor variability (see below).

\section{Variation between tissues derived from different human subjects}

Explants from 40 different human donors were cultured identically, infected with strain K454 and incubated for $18 \mathrm{~h}$. After this period of time triplicate explants from each donor were treated with sodium taurocholate or left untreated and then homogenized prior to viable counting. Amongst the 40 donors, six were smokers, there were 19 females, 21 males, and 16 of the explants were resected during the winter months (November to $\mathrm{March}$ ). The mean inoculum was $3.9 \pm 1.56 \times 10^{7}$ (range $\left.2 \times 10^{6}-9 \times 10^{7}\right)$. The mean recovery of $N$. meningitidis from untreated explants after $4 \mathrm{~h}$ of infection was $160 \cdot 2 \pm 49 \cdot 7$ c.f.u. (mg tissue) ${ }^{-1}$ (range $\left.2 \cdot 6-1578 \cdot 95\right)$, rising to $47717 \pm 25190$ c.f.u. $\mathrm{mg}^{-1}$ (range 30937500 c.f.u. $\mathrm{mg}^{-1}$ ) after $18 \mathrm{~h}$ incubation. The recovery of bacteria from sodium-taurocholate-treated explants after $4 \mathrm{~h}$ incubation was $2.35 \pm 0.88$ c.f.u. $\mathrm{mg}^{-1}$ (range 0-30.3 c.f.u. $\mathrm{mg}^{-1}$ ) rising to $4093 \pm 3026$ c.f.u. $\mathrm{mg}^{-1}$

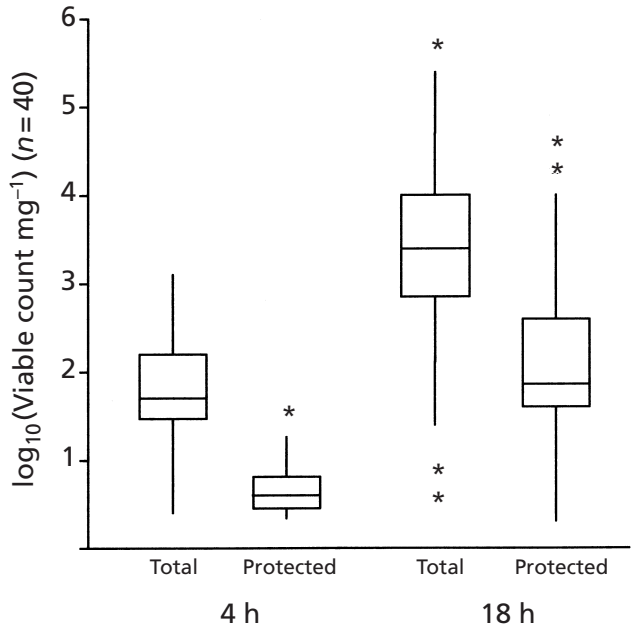

Fig. 2. Box-and-whisker plots of $N$. meningitidis recovery from identically harvested explants derived from 40 human adult donors which were experimentally infected with strain K454 N. meningitidis. Plots are shown for total bacteria recovered from washed explants ('total') and (as an estimate of invasion) from sodium-taurocholate-treated explants ('protected'). Outliers are plotted with asterisks.

(range 3-120000 c.f.u. $\mathrm{mg}^{-1}$ ) after $18 \mathrm{~h}$ incubation. The mean invasive fraction at $4 \mathrm{~h}$ was $0.021 \pm 0.009$ at $4 \mathrm{~h}$, and $0 \cdot 118 \pm 0 \cdot 027$ at $18 \mathrm{~h}$. There was no effect of smoking, season or sex on the recovery of bacteria from explants, by analysis of variance.

Variance of recovery of bacteria from explants is illustrated in Fig. 2. Analysis of triplicate data derived from individual donor tissues showed that the methods were highly reliable, with an intraclass correlation at $4 \mathrm{~h}$ of 0.988 , and at $18 \mathrm{~h}$ of 0.968 (of c.f.u. per $\mathrm{mg}$ of untreated explants). When recovered viable counts were adjusted for minor variation of the inoculum size, the 
coefficient of variation of recovered viable counts from untreated explants was $1335 \%$ after $4 \mathrm{~h}$ incubation, and $77 \%$ after $18 \mathrm{~h}$ incubation.

\section{DISCUSSION}

An organ culture model was used to measure the survival of Neisseria spp. on and within human nasopharyngeal mucosa, and the results indicate that the model is able to discriminate between N. meningitidis, and representative strains of $N$. lactamica and $N$. animalis. There were clear differences in survival within the mucosa of clonally diverse strains of N. meningitidis. Survival of $N$. meningitidis within nasopharyngeal tissue varied widely between mucosae derived from different human hosts, at least in the model used in this study. The experimental period of $18 \mathrm{~h}$ was sufficiently long to permit emergence of any variants with invasive potential.

Overall survival of Neisseria within the mucosa was measured by homogenizing washed explants infected with organisms over variable lengths of time. The use of sodium taurocholate to kill extramucosal bacteria is reasonable; compared with other bile salts, sodium taurocholate has a low $\mathrm{pK}_{\mathrm{a}}$ and requires specialized active transport for efficient penetration of epithelial cells (Shiau, 1987). Invasion of nasopharyngeal explants by $N$. meningitidis is an active process of parasitedirected endocytosis (Stephens et al., 1983; Read et al., 1995). During this process, bacteria are enveloped by microvillous extensions from the cell surface, a process requiring host cell cytoskeletal rearrangement, which in turn requires polymerization of actin filaments. Failure to recover any bacteria from cytochalasin D-exposed explants after treatment with sodium taurocholate (in contrast to explants not exposed to cytochalasin D) suggests that sodium taurocholate kills all bacteria which have not invaded the mucosa as a result of endocytosis, or some other process requiring an active host response. We demonstrated no bactericidal activity of homogenates of sodium-taurocholate-treated explants, indicating that sodium taurocholate did not penetrate this tissue. We also demonstrated absence of meningococci on the surface of sodium-taurocholatetreated infected explants and were only able to retrieve meningococci from such explants once they had been homogenized. This suggests that sodium taurocholate treatment kills extra-mucosal bacteria, but does not kill bacteria within a protected site deep within the mucosa. Sodium taurocholate kills bacteria rapidly, in contrast with gentamicin (which is often used for similar assays of invasion), which requires prolonged periods of incubation for bactericidal activity.

We found that high inocula $\left(10^{7}\right.$ c.f.u.) of $N$. meningitidis were required for consistent meningococcal survival in this model. Inocula of $10^{5}$ c.f.u. or below failed to thrive, whilst an inoculum of $10^{6}$ c.f.u. did not result in survival of sufficiently high numbers within the tissue. The natural inoculum during droplet transmission between humans cannot be accurately measured, but is probably orders of magnitude below that used in this model. On the other hand, the surface area of mucosa available for epithelial contact by droplet-associated Neisseria during natural transmission is very much higher than that available in this experimental method.

The failure of $N$. animalis to thrive in this experimental model is consistent with its habitat - it has never been isolated from humans but does colonize a range of small mammals including guinea pigs (Morse \& Genco, 1998). $N$. lactamica survived in relatively low numbers but, in contrast to $N$. meningitidis, could not be recovered from sodium-taurocholate-treated explants. The behaviour of single strains should not be overinterpreted but these data suggest that survival of Neisseria spp. within nasal mucosa may correlate with pathogenicity. However, the survival of diverse isolates of $N$. meningitidis was not uniform in these experiments. Meningococci belonging to the subgroups of serogroup A could not be recovered from an intramucosal site, whereas the representative isolates of the ET-37 complex, lineage III and ET-5 complex did invade and grow intramucosally. These observations are intriguing, given the diverse epidemiologies of different meningococcal lineages. Strains belonging to the subgroups of serogroup A cause largescale epidemics and pandemics in China and Africa, but have caused virtually no disease in Western Europe and North America since the Second World War (Schwartz et al., 1989). By contrast, ET-37 complex meningococci cause up to $40 \%$ of meningococcal disease in European and American countries and are commonly associated with institutional outbreaks of serogroup $\mathrm{C}$ disease. Members of the ET-5 complex were responsible for the spread of hyperendemic meningococcal disease during the 1970s and 1980s in Western Europe, but were largely replaced as a major cause of meningococcal disease in many countries by organisms belonging to lineage III. The reasons for these diverse epidemiologies are not completely understood, but it is thought that ET-5 complex and lineage III organisms, for example, may have prolonged carriage compared to meningococci belonging to the subgroups of serogroup A. The $t_{\frac{1}{2}}$ of carriage of serogroup A meningococci is 1 month, whereas the $t_{\frac{1}{3}}$ of carriage of meningococci belonging to other serogroups is about 3 months (Blakebrough et al., 1982).

Our data suggest that differences in the potential of genetically diverse meningococci to penetrate human nasopharyngeal mucosa can be measured in this model system, potentially yielding information valuable to the understanding of meningococcal epidemiology and pathogenesis. This diversity of invasion and intramucosal growth is likely due to a combination of several meningococcal cellular components, including outermembrane proteins, capsule, IgA protease and pili (Nassif et al., 1999). Although Opa and PilC have been clearly shown to influence successful attachment to epithelial cell monolayers and organ culture mucosa (Virji et al., 1992, 1993; Rayner et al., 1995) the data presented here suggest that other meningococcal determinants are also required for survival within the mucosa. 
More experimentation using organ culture systems is required to address these issues, perhaps employing isogenic meningococcal constructs. The availability of whole genome sequences for comparison of serogroup A subgroup (IV) (Parkhill et al., 2000) with a member of the ET-5 complex (Tettelin et al., 2000) will open up new possibilities for developing further these observations in this in vitro model.

One remarkable finding was the very wide variation in the recovery of meningococci from nasopharyngeal explants derived from different humans, which was initially apparent in experiments investigating differences between Neisseria species and clonal groups (Tables 2 and 3). This was then formally tested using tissue from 40 human donors (Fig. 2). Experiments were conducted in triplicate and there was very little variation between explants derived from an individual host. However, the coefficient of variation across the group of 40 individuals was $1335 \%$ after $4 \mathrm{~h}$ and $77 \%$ after $24 \mathrm{~h}$ incubation. This is dramatic inter-subject variability - in comparison, the coefficient of variation of the human haematocrit is $9 \%$, and that of the height of 17 -year-old males is only $3.4 \%$ (Lentner, 1984). As the experimental methodology was uniform across the 40 individuals studied, the variation that was observed was likely due to genetic or environmental influences upon the host tissue. All of the individuals who donated tissue in this survey were suffering from non-allergic nasal obstruction, mainly due to septal deviation. None were receiving intranasal topical steroids, though clearly we cannot exclude the influence of disease comorbidities secondary to the upper respiratory tract obstruction. Other possible environmental influences that could explain this variation include recent respiratory tract infection, though there was no correlation with season. It is unlikely that anti-meningococcal antibody present in the mucosae was responsible for the variation observed, as the tissue employed is not lymphoid, and we have not detected antibody to common viruses (e.g. influenza) in tissue homogenates (Read et al., 1999).

Epidemiologically, there is support for the notion of a genetic influence on successful colonization and invasion. Within communities, nasopharyngeal colonization by $N$. meningitidis is only rarely complicated by invasive disease, even amongst those who do not possess serogroup- or serotype-specific antibodies (Goldschneider et al., 1969). Likewise, individuals differ in the characteristics of nasopharyngeal carriage of meningococci. Rake (1934) followed the nasopharyngeal carriage of meningococci of groups of individuals over a period of 2 years. This included one group in a confined meningococcal laboratory amongst whom $50 \%$ were never colonized despite the fact that they are likely to have been engaged regularly in oral pipetting of meningococcal cultures. Amongst those who became colonized, there were three patterns: some were transient, some were intermittent and others were chronic carriers of the meningococcus. This pattern was also observed in young children in a nursery school environment (Rake, 1934).
We conclude that the distinctive colonization and disease potential of Neisseria spp. may be partially a consequence of their ability to invade and survive within human nasopharyngeal mucosa, but that this is influenced greatly by host or environmental factors.

\section{ACKNOWLEDGEMENTS}

This work was supported by grants from the Wellcome Trust, Meningitis Research Foundation, and Sheffield University Hospitals' Charitable Trust.

We would like to thank the Theatre Sister and Staff of the ENT Theatre, Royal Hallamshire Hospital, and also Pauline Whitaker and Ian Geary for help with the preparation of this manuscript. We are grateful to Janet Suker of the National Institute for Biological Standards and Control, and to Xavier Nassif, Philippe Morand and James Moir for provision of antibodies.

\section{REFERENCES}

Blakebrough, I. S., Greenwood, B. M., Whittle, H. C., Bradley, A. K. \& Gilles, H. M. (1982). The epidemiology of infections due to Neisseria meningitidis and Neisseria lactamica in a Northern Nigerian community. J Infect Dis 146, 626-637.

Broome, C. V. (1986). The carrier state: Neisseria meningitidis. J Antimicrob Chemother 18 suppl A., 25-34.

Cartwright, K. A. V., Stuart, J. M., Jones, D. M. \& Noah, M. D. (1987). The Stonehouse Survey: nasopharyngeal carriage of meningococci and Neisseria lactamica. Epidemiol Infect 99, 591-601.

Coen, P. G., Cartwright, K. \& Stuart, J. (2000). Mathematical modelling of infection and disease due to Neisseria meningitidis and Neisseria lactamica. Int J Epidemiol 29, 180-188.

de Vries, I.-P., van der Ende, A., van Putten, J. P. M. \& Dankert, J. (1996). Invasion of primary nasopharyngeal cells by Neisseria meningitidis is controlled by phase variation of multiple surface antigens. Infect Immun 64, 2998-3006.

Gold, R., Goldschneider, I., Lepow, M. L., Draper, T. F. \& Randolph, M. (1978). Carriage of Neisseria meningitidis and Neisseria lactamica in infants and children. J Infect Dis 137, 112-121.

Goldschneider, I., Gotschich, E. C. \& Artenstein, M. S. (1969). Human immunity to the meningococcus. I. The role of human antibodies. J Exp Med 129, 1307-1326.

Greenfield, S. \& Feldman, H. (1967). Familial carriers and meningococcal meningitis. N Engl J Med 277, 497-502.

Jackson, A. D., Cole, P. \& Wilson, R. (1996). Comparison of Haemophilus influenzae type B infection of human respiratory mucosa organ cultures maintained with an "air interface'. Infect Immun 64, 2353-2355.

Lentner, C. (editor) (1984). Geigy Scientific Tables III. Basle: Ciba-Geigy.

Morse, S. A. \& Genco, C. A. (1998). Neisseria. In Topley and Wilson's Systematic Bacteriology, pp. 877-888. Edited by A. Balos \& B. I. Duerden. New York: Arnold.

Nassif, X., Pujol, C., Morand, P. \& Eugene, E. (1999). Interactions of pathogenic Neisseria with host cells. Is it possible to assemble the puzzle? Mol Microbiol 32, 1124-1132.

Olcen, P., Kjellander, J., Danielsson, D. \& Lindquist, B. L. (1979). Culture diagnosis of meningococcal carriers: yield from different 
sites and influence of storage in transport medium. J Clin Pathol 32, 1222-1225.

Parkill, J. A. M., Achtman, M., James, K. D., Bentley, S. D. \& 24 other authors (2000). Complete DNA sequence of a serogroup A strain of Neisseria meningitidis Z2491. Nature 404, 502-506.

Rake, G. (1934). Studies of meningococcus infection; the carrier problem. J Exp Med 59, 553-576.

Rayner, C. F. J., Dewar, A., Moxon, E. R., Virji, M. \& Wilson, R. (1995). The effect of variations in the expression of pili on the interaction of Neisseria meningitidis with human nasopharyngeal epithelium. J Infect Dis 171, 113-121.

Read, R. C. \& Goodwin, L. (2001). Experimental nasopharyngeal colonization by Neisseria meningitidis using explant organ culture. In Meningococcal Disease, Methods and Protocols, Methods in Molecular Medicine Series, pp. 621-634. Edited by A. J. Pollard \& M. C. Maiden. Totowa, NJ: Humana.

Read, R. C., Fox, A., Miller, K., Gray, T., Jones, N., Borrow, R., Jones, D. M. \& Finch, R. G. (1995). Experimental infection of human nasal mucosal explants with Neisseria meningitidis. J Med Microbiol 42, 353-361.

Read, R. C., Goodwin, L., Parsons, M. A., Silcocks, P., Kaczmarski, E. B., Parker, A. \& Baldwin, T. O. (1999). Co-infection with influenza B virus does not affect association of Neisseria meningitidis with human nasopharyngeal mucosa in vitro. Infect Immun 67, 3082-3086.

Riordan, T., Cartwright, K., Andrews, N. \& 7 other authors (1998). Acquisition and carriage of meningococci in marine commando recruits. Epidemiol Infect 121, 495-505.

Schwartz, B., Moore, P. \& Broome, C. V. (1989). Global epidemiology of meningococcal disease. Clin Rev Microbiol 2, S118-S124.
Shiau, Y.-F. (1987). Lipid digestion and absorption. In Physiology of the Gastrointestinal Tract, pp. 1527-1555. Edited by L. R. Johnson. New York: Raven Press.

Sim, R. J., Harrison, M. M., Moxon, E. R. \& Tang, C. M. (2000). Underestimation of meningococci in tonsillar tissue by nasopharyngeal sampling. Lancet 356, 1653-1654.

Stephens, D. S., Hoffman, L. H. \& McGee, Z. A. (1983). Interaction of Neisseria meningitidis with human nasopharyngeal mucosa: attachment and entry into columnar epithelial cells. J Infect Dis 148, 369-376.

Stephens, D. S., Spellman, P. A. \& Swartley, J. S. (1993). Effect of the $(\alpha 2 \rightarrow 8)$-linked polysialic acid capsule on adherence of Neisseria meningitidis to human mucosal cells. J Infect Dis 167, 475-479.

Stuart, J. M., Cartwright, K. A., Robinson, P. M. \& Noah, N. D. (1989). Effect of smoking on meningococcal carriage. Lancet $\mathbf{8 6 5}$, $723-725$.

Tettelin, H., Saunders, N. J., Heidelberg, J. \& 39 other authors (2000). Complete genome sequence of Neisseria meningitidis serogroup B strain MC58. Science 287, 1809-1815.

Virji, M., Alexandrescu, C., Ferguson, D. J. P., Saunders, J. R. \& Moxon, E. R. (1992). Variations in the expression of pili : the effect on adherence of Neisseria meningitidis to human epithelial and endothelial cells. Mol Microbiol 6, 1271-1279.

Virji, M., Makepeace, K., Ferguson, D. J. P., Achtman, M. \& Moxon, E. R. (1993). Meningococcal Opa and Opc proteins: their role in colonization and invasion of human epithelial and endothelial cells. Mol Microbiol 10, 499-510.

Received 20 September 2001; accepted 2 January 2002 